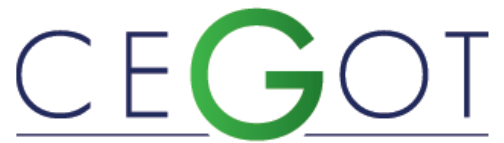

Centro de Estudos de Geografia e Ordenamento do Território
Geografia e Ordenamento do Território, Revista Eletrónica

Centro de Estudos de Geografia e Ordenamento do Território http://cegot.org

TRAVASSOS, LUCIANA

Universidade Federal do $A B C$ - UFABC

UFABC. Alameda da Universidade, s/n Delta, sala 370 - Anchieta, São

Bernardo do Campo - SP, 09606-045, Brasil

luciana.travassos@ufabc.edu.br

PORTES, BRUNO

Universidade Federal do $A B C$ - UFABC

Rua Visconde de Parnaíba, 305. Apto 54. Brás. São Paulo - SP. 03045-000,

Brasil

bcportes@gmail.com

\title{
Rural metropolitano: caracterização e regulação na Região Metropolitana de São Paulo (Brasil)
}

Metropolitan rural: characterization and regulation in the Metropolitan Region of São Paulo (Brazil)

Referência: Travassos, Luciana; Portes, Bruno (2018). Rural metropolitano: caracterização e regulação na Região Metropolitana de São Paulo (Brasil). Revista de Geografia e Ordenamento do Território (GOT), n. ${ }^{\circ} 14$ (setembro). Centro de Estudos de Geografia e Ordenamento do Território, p. 359-380, dx.doi.org/10.17127/got/2018.14.015

\section{RESUMO}

Os estudos acerca do rural brasileiro têm avançado no reconhecimento da heterogeneidade destes territórios, subsidiando políticas de desenvolvimento rural. Contudo, estes estudos não consideram os municípios localizados em regiões metropolitanas e a ruralidade neles presente. Além disso, como pode ser observado na Região Metropolitana de São Paulo (RMSP), as características que permitem a identificação do território rural nestes contextos convivem com uma extensa periferia fragmentada, que permanece em processo de crescimento demográfico. A regulamentação de uso da terra também não enxerga sua a complexidade, o que contribui para fragilizar o rural nesse contexto. Este artigo faz uma revisão da literatura a respeito dos conceitos de nova ruralidade e de periurbano, apresenta as características do rural metropolitano na RMSP, a fim de fomentar a discussão sobre sua caracterização e regulação.

Palavras-chave: rural metropolitano; nova ruralidade; periurbano; planejamento territorial.

\section{ABSTRACT}

The studies about the Brazilian rural have advanced in the recognition of the heterogeneity of these territories, subsidizing policies of rural development. However, these studies do not consider the municipalities located in metropolitan regions and its rurality. Moreover, as can be observed in the Metropolitan Region of São Paulo (MRSP), the characteristics that allow the identification of the rural territory in these contexts coexist with an extensive fragmented periphery, which remains in a process of demographic growth. The regulation of land use also does not see its complexity, which contributes to weakening the rural in this context. This article reviews the literature on the concepts of new rurality and periurban, 
presents the characteristics of the metropolitan rural in the MRSP, in order to foment the discussion about its characterization and regulation.

Keywords: metropolitan rural; new rurality; peri-urban; spatial planning

\section{Introdução}

Há, no campo dos estudos rurais brasileiros - e internacionais - uma mudança de paradigma na maneira com a qual se enxerga o mundo rural. A abordagem tradicional que relaciona o rural à atividade setorial agrícola e ao atraso socioeconômico, tem dado espaço a uma abordagem que questiona o lugar que lhe é conferido no processo de desenvolvimento. Partindo de uma visão na qual o desenvolvimento não se restringe aos grandes centros urbanos, esta perspectiva enxerga o rural como um espaço cada vez mais valioso nas sociedades contemporâneas, com dinâmicas, atores e atividades que vão além da agricultura. (Abramovay, 2003; Favareto e Wanderley, 2013; Regidor, 2003)

Embora estejam presentes em diversos países, estas dinâmicas não ocorrem de maneira uniforme no espaço e, muito menos, as diferentes configurações rurais respondem a elas da mesma maneira, conferindo ao rural contemporâneo um caráter extremamente diverso e dinâmico (Berdegué, et al., 2012). Assim, o reconhecimento desta diversidade e dinamismo tem consequências fundamentais para o processo de planejamento:

No Brasil, a divisão do que é urbano e rural se pauta em critérios administrativos, que não consideram as dinâmicas e a heterogeneidade destes espaços. No intuito de superar este critério e elaborar ferramentas para políticas territoriais, foram desenvolvidas recentemente algumas propostas de tipologias rurais brasileiras. Dentre elas, destacam-se o projeto Tipologia Regionalizada dos Espaços Rurais Brasileiros (Bitoun et al., 2017) e uma proposta de reestruturação e classificação dos espaços rurais feita pelo Instituto Brasileiro de Geografia e Estatística (IBGE, 2017). Entretanto, mesmo nestas propostas contemporâneas há dificuldade em capturar o rural metropolitano, que se mostra ausente na primeira e subdimensionado, na segunda.

De fato, o rural presente nas metrópoles brasileiras padece de grande invisibilidade, uma vez que não é alcançado pelas políticas rurais e se encontra a reboque das políticas urbanas, 
sendo, muitas vezes, considerado - quando não há proteção de cunho ambiental - como estoque de terras para a urbanização.

Porém, considerando a Região Metropolitana de São Paulo (RMSP) a mais populosa região metropolitana brasileira e da América do Sul, pode-se notar que nas franjas urbanas estão presentes tanto elementos que remetem ao conceito de nova ruralidade - pluriatividade e multifuncionalidade, em proximidade com as dinâmicas da natureza -, quanto características que remetem ao conceito de periurbano (Travassos \& Ferreira, 2016).

Assim, o presente artigo visa contribuir com a discussão do rural e da ruralidade nos municípios pertencentes a metrópoles e capitais regionais, focando a Região Metropolitana de São Paulo (RMSP), a fim de compreender as dinâmicas que configuram estes espaços e os desafios de regulação, em um contexto que tem como consequência o enfraquecimento da manutenção desses territórios. Para tanto se elaborou uma da revisão da bibliografia atual a respeito dos conceitos de espaço rural e periurbano e uma breve contextualização a partir do arcabouço jurídico, de dados existentes e pesquisa empírica na RMSP.

\section{As diversas conceituações do rural}

Apesar das diversas abordagens e critérios utilizados por diferentes autores, alguns elementos se mostram recorrentes na bibliografia quando se trata de compreender a essência do espaço rural, que variam desde a abundância de áreas verdes ou naturais até as relações e representações de ruralidade (Kageyama, 2008).

Uma primeira abordagem considera a ruralidade quanto a sua localização geográfica, que consiste em algum grau de $\operatorname{distância~}^{1}$ (remoteness), isto é, o rural sendo, sob alguns aspectos, uma área afastada ou isolada. Esta distância pode ser tanto econômica, sendo o rural o espaço com maiores custos para superá-la, quanto em oposição ao urbano. Nesta perspectiva, o rural é entendido como o espaço onde há menor número ou maior dificuldade de acessos ou contatos, devido à baixa densidade populacional e à maior

\footnotetext{
${ }^{1}$ HITE, James. The Thünen model as a paradigm for rural development. Clemson university, 1999; HOOVE, Edgar M.; GIARRATANI, Frank. An introduction to Regional Economics. 1999.
} 
distância entre as unidades produtivas e entre os agentes e os mercados (Kageyama, 2008). Com relação às características espaciais, outros autores ${ }^{2}$ definem o rural como o lugar onde há uma abundância relativa de terras e recursos naturais, com pequenas manchas de assentamentos humanos e infraestruturas.

Outra abordagem muito presente nas tentativas de definir o rural contemporâneo parte de uma crítica à visão tradicional que associa o campo ao espaço da atividade agrícola e ao atraso material e cultural, em oposição ao moderno representado pela cidade, pela indústria e pelo urbano.

Esta postura está relacionada com o fato de haver, nas últimas décadas, a revalorização de determinadas áreas rurais e o seu consequente crescimento populacional, bastante presente nos países europeus e norte-americanos. Muitas vezes relacionado à presença crescente de atores ligados a atividades não-agrícolas, este dinamismo tem motivado uma agenda de pesquisa internacional em busca de compreender, conceituar e elaborar políticas que reconheçam esta nova ruralidade (Marques, 2002).

Dentre estes processos, destacam-se: a) o aumento da diversidade de usos no rural com novas funções não exclusivamente produtivas (residência, paisagem, esporte e lazer); b) o consequente aumento dos empregos não-agrícolas e redução dos empregos agrícolas; e c) o menor crescimento dos grandes centros urbanos, relacionado também a um aumento da procura do rural por diversos segmentos populacionais (Kageyama, 2008).

As características desta nova ruralidade podem ser reunidas em cinco questões (Kageyama, 2008) ${ }^{3}$ : a) diversificação social em função das novas atividades não produtivas desempenhadas no rural; b) o estabelecimento de relações de complementaridade com o urbano, em substituição ao caráter de antagonismo; c) o crescimento demográfico, pela redução das migrações para a cidade e atração de outras categorias sociais; d) a valorização do patrimônio natural e cultural das localidades, que passa a ser percebido como elemento de desenvolvimento local e; e) os novos contornos da questão agrária, que passam a

\footnotetext{
${ }^{2}$ WIGGINS, Steve; PROCTOR, sharon. How special are rural areas? The economic implications of location for rural development. Development Policy Review, v. 19, n. 4, 2001, p. 427-436.

${ }^{3}$ Tais características gerais foram elencadas pela autora com base nas contribuições de GÓMEZ, E. Sergio. Nueva Ruralidad? Un aporte al debate. Estudos Sociedade e Agricultura. Rio de Janeiro, UFRJ/CPDA, n. 17, out/2001; e WANDERLEY, Maria Nazareth B. A emergência de uma nova ruralidade nas sociedades modernas avançadas - o "rural" como espaço singular e ator coletivo. Estudos Sociedade e Agricultura, n.15, out/2000.
} 
considerar os papéis dos agricultores na segurança alimentar, preservação do meio ambiente e da paisagem rural.

Nestas abordagens se mostra bastante presente a perspectiva territorial do rural, enquanto espaço dotado de uma forte estruturação interna, com relações de diversas naturezas com o urbano. Além disso, a abordagem territorial do rural parte da premissa de que este espaço apresenta ampla diversidade (Abramovay, 2003; Favareto e Wanderley, 2013), tanto em função das características biofísicas do ambiente em que se insere ${ }^{4}$, quanto das estruturas sociais e instituições informais que se reproduzem no tempo e no espaço, configurando diversas territorialidades ${ }^{5}$ (Bitoun et. al, 2017; Berdegué et al, 2012).

Abramovay (2003) sistematiza as características do rural em três dimensões. Primeiro entende que "a ruralidade supõe, em última análise, o contato mais imediato dos habitantes locais com o meio natural que os habitantes urbanos" (p.25). Em segundo lugar, a relativa dispersão populacional, na qual tomam corpo as relações interpessoais no rural, os laços de proximidade e vizinhança entre os indivíduos e famílias, de ajuda mútua. Por último, a inserção do rural nas dinâmicas urbanas se dá tanto na formação de polos rurais (pequenos e médios assentamentos que concentram os serviços básicos) quanto na maior ou menor dependência dos espaços rurais com os centros metropolitanos.

Nesta visão, a ruralidade se configura cada vez mais como um valor para as sociedades contemporâneas. Esta busca do contato com o campo pelos habitantes urbanos pode ser observada na análise de Silva (2007), que mostra a procura pelo turismo em espaços rurais por grupos urbanos de classe média, a fim de romper com o cotidiano e ir ao encontro de uma experiência revigorante no campo. Neste estudo, chama à atenção o fato desta procura se relacionar com uma busca identitária, de conhecimento das suas origens, tradições e patrimônio histórico, reforçando o valor deste espaço. Esta dinâmica se mostra bastante presente no contexto europeu, sobretudo a partir dos anos 1980 . Muitas vezes

\footnotetext{
${ }^{4}$ Esta relação pode ser observada com mais detalhes no projeto Tipologia Regionalizada dos Espaços Rurais Brasileiros (Bitoun, et al, 2017), no qual optou -se por estabelecer uma divisão de partida com base nos biomas nacionais (Amazônia, Pantanal, Cerrado, Mata Atlântica, Caatinga e Pampa), separando também os municípios situados na Linha de Costa.

${ }^{5}$ No âmbito do programa Dinamicas Territoriales Rurales en America Latina (Berdegué, et al, 2012) buscou-se compreender a diversidade do rural latino-americano a partir de um estudo das mudanças nas estruturas sociais e arranjos institucionais de determinados territórios que resultaram no rompimento com a trajetória predominante de estagnação econômica e pobreza nestes territórios.
} 
dependentes de determinações macrorregionais ou globais, como a Política Agrícola Comum (PAC) e Organização Mundial do Comércio (OMC), nos territórios rurais passa a ser recorrente a promoção de cultura como estratégia de desenvolvimento local, tendo como fundamento as "identidades locais" que criam e recriam um sentido de lugar. (Marques, 2008).

A estruturação de economias locais e regionais também origina diferentes conformações do rural, que variam tanto em função do tamanho e da proximidade das cidades com as áreas rurais, quanto da integração entre espaço, atividades, sociedade, cultura e instituições que configuram estas economias (Kageyama, 2008). Em estudo realizado pelo Agricultural Economics Research Institute (LEI, 2006), observa-se que, em diversos países europeus, a busca pelo uso recreativo do rural tem se mostrado bastante frequente naqueles localizados na proximidade de áreas metropolitanas, o que traz tanto desafios quanto potencialidades de desenvolvimento local. Marques (2015) aponta que a própria a atividade agrícola, embora reduzida nos países europeus, apresenta, nas áreas metropolitanas, um novo potencial de desenvolvimento, voltado à busca pela paisagem e estética rural, aos valores imateriais da cultura camponesa e ao turismo gastronômico.

No Brasil, Favareto e Wanderley (2013) chamam à atenção para alguns fatores determinantes na configuração específica de seu rural: a incidência da pobreza sobre a população que vive no campo, como consequência das restrições no acesso à terra e das condições degradantes do trabalho no setor agrícola; a composição da população rural significativamente diferente dos países desenvolvidos, nos quais os efeitos modernizadores atingiram de forma mais homogênea o conjunto da sociedade, inclusive sua parte rural, de modo que viver no campo não impede o acesso às "amenidades urbanas"; a enorme proporção do êxodo rural, particularizado no caso da modernização agrícola brasileira por ter se dado menos pelo que se introduziu de moderno e mais pela reprodução de formas tradicionais de dominação no campo, resultando na expulsão da grande maioria dos trabalhadores não proprietários de suas terras e a inviabilização das condições mínimas de reprodução do campesinato.

Assim, é possível concluir que as mudanças no conceito de rural expressam, principalmente, uma mudança de uma visão setorial para uma abordagem territorial e, nesta, a leitura de dinâmicas territoriais contemporâneas que conformam uma diversidade de atividades e 
modos de vida. No Brasil, estas dinâmicas guardam características que as particularizam, em especial relacionadas às excludentes formas de produção do espaço, tanto rural quanto urbana.

\section{O periurbano em questão}

Apesar de grande parte da literatura sobre o rural buscar defini-lo, seja por um viés substantivista - buscando características inerentes a este espaço -, ou por um viés relacional - considerando o rural como oposição ou complemento do urbano (Kageyama, 2008) -, quando se trata de caracterizar o rural situado em áreas metropolitanas, alguns fatores tornam esta tarefa mais complexa. Como pode ser observado na RMSP, onde as franjas metropolitanas apresentam uma morfologia fragmentada, tanto os atributos que caracterizam a ruralidade quanto os limites entre o urbano e o rural não se mostram com clareza. Segundo Travassos e Ferreira (2016), a difícil caracterização deste espaço se dá tanto em função da alta complexidade de usos do solo e sua transitoriedade - que lhe confere um caráter periurbano -, quanto pela dualidade expressiva nas políticas voltadas para esta área havendo por um lado, políticas de proteção ambiental e por outro, políticas voltadas às demandas urbanas.

Quanto à dificuldade de definição conceitual e delimitação do periurbano, Barsky (2005) elucida que este espaço expressa uma situação transicional, de interface entre dois tipos geográficos aparentemente bem diferentes - o campo e a cidade -, sendo um espaço que se define pela indefinição: não é campo, nem cidade. Trata-se, assim, de um território em consolidação, bastante instável quanto à constituição de redes sociais e de grande heterogeneidade nos usos do solo. Segundo o autor, outro fator que dificulta sua definição é o fato destes territórios terem sido analisados a partir de diversas abordagens conceituais: a periferia urbana, o rur-urbano, a "cidade difusa", a fronteira campo-cidade, a "cidade dispersa", territórios de borda, borda urbana/periurbana, o contorno da cidade, extraradio, exurbia. 
Com base neste entendimento, Barsky (2005) elenca abordagens de diversos campos do conhecimento, que podem fornecer elementos para a compreensão das relações que as cidades estabelecem com seu entorno.

A geografia e o planejamento urbano possuem grande contribuição nesta temática com dois enfoques principais: do início do século XX, até o final da década de 1970, os estudos focam a expansão urbana horizontal, a "urbanização do campo", "urbanização difusa" e as transformações do rural pelo avanço da urbanização. A partir da década de 1980, os estudos das periferias urbanas em si - e da agricultura periurbana em particular - e do planejamento destas áreas ganham relevância, em especial nos documentos dos organismos multilaterais.

Cardoso e Fritschy (2012) discutem a definição do conceito de espaço rururbano contemporâneo a partir de uma perspectiva do rural que dialoga com alguns autores apresentados anteriormente, reforçando a crítica à visão dicotômica entre as polaridades urbanas e rurais e adotando o conceito de continuum rural-urbano.

Valenzuela Rubio também define o periurbano como um espaço contínuo, mas coloca que nele há um predomínio urbano, embora abrigue usos que vão desde polígonos industriais até espaços de agricultura residual (Cardoso e Fritschy, 2012). Tal definição aproxima o conceito de periurbano à cidade em expansão, bastante próximo de uma definição de formação da periferia, quando consideradas as cidades brasileiras.

Referindo-se às contribuições de García Ramón (1995), Cardoso e Fritschy (2012) destacam que ao analisar as dinâmicas territoriais que dão origem ao espaço periurbano, este autor busca defini-lo em relação ao espaço rururbano, a diferença conceitual entre os termos pressão dos usos urbanos sobre os usos do solo agrícola, que é maior no periurbano (Cardoso e Fritschy, 2012,).

Outra diferença entre eles está na origem de seus processos geradores: enquanto o periurbano se conformou pelo avanço da cidade, no sentido centrífugo de população urbana e atividades econômicas, no rururbano se deu uma combinação de processos, em distintas escalas temporais e espaciais, dos quais se destacam: a) a chegada no campo de populações advindas das cidades, como aposentados ou migrantes sazonais que adquirem no campo a segunda residência; b) a busca do setor hoteleiro e de comércio pelo espaço 
onde a paisagem é valorizada e; c) a permanência de áreas com atividades agrícolas, nas quais predominam a população rural original, estabilizada e com pouca ou nenhuma migração (Cardoso e Fritschy, 2012).

Cabe aqui a ressalva de que, quando se discute o espaço periurbano enquanto área de transição, se faria necessário compreender a priori o que se entende por urbano e rural, o que não tem se mostrado claramente definido na literatura analisada. Em alguns autores analisados neste trabalho, ao tratar da conceituação do periurbano observa-se a associação do rural como espaço de realização da atividade agrícola, numa visão simplificadora deste espaço que, como apresentado anteriormente, é bastante refutada pelos pesquisadores que defendem a emergência de uma nova ruralidade.

$\mathrm{Na}$ literatura brasileira, Furtado (2007) defende a necessidade de se avançar na compreensão das Áreas de Interface Periurbana (AIP), tanto em sua definição, quanto no planejamento e gestão urbana e regional que as envolve.

Em breve revisão crítica da evolução dos estudos da interface periurbana, a autora discorre a respeito dos "conceitos tradicionais" que tem na literatura francesa maior robustez e homogeneidade, destacando quatro temas centrais abordados: a) a importância da agricultura periurbana e das relações com o rural, mais presentes no contexto africano que no latino-americano; b) a importância da economia informal nas áreas periurbanas, sobretudo a autoconstrução das moradias, compra e aluguel informal de terra e casas e atividades clandestinas; c) conflitos sobre propriedade da terra, invasões, condomínios clandestinos, especuladores informais e sistemas duais de mercados de terras (formais e informais) e; d) Processos demográficos baseados nas invasões organizadas de terras, nos loteamentos especulativos de áreas rurais e na realocação de moradores de assentamentos precários urbanos.

Quanto aos conceitos mais recentes, a autora aponta que:

\footnotetext{
"segundo estudo das Nottingham and Liverpool Universities (1998), a questão central é a dificuldade conceitual em se construir uma estrutura espacial sobre o que é essencialmente um local amorfo e móvel, onde se dá a interação de vários processos e interligações entre o rural e o urbano, de natureza social, econômica e cultural" (Furtado, 2007, p.4).
}

Furtado (2007) conclui que mesmo nas conceituações mais recentes, destaca-se a ideia de que a mudança ou evolução das áreas periurbanas se dá no sentido das cidades para fora, 
em que as áreas periurbanas são como áreas pré-urbanas, que com o tempo farão parte da cidade. Segundo a autora, "por trás dessa visão está uma concepção da cidade como lugar central e que cresce continuamente, e do campo como lugar estático" (p.5).

Todavia, Furtado (2007) aponta que esta concepção está sendo cada vez mais criticada e substituída por "uma percepção das áreas periurbanas como o espaço onde processos urbanos e rurais de natureza ecológica, socioeconômica e cultural interagem e configuram um território" (p.6).

Neste processo, é possível concluir que o periurbano apresenta uma série de características, expressivas no caso das metrópoles brasileiras, como: a) composição social heterogênea; b) grande crescimento demográfico; c) usos heterogêneos; d) grande dinâmica de transformações físicas; e) superexploração de estruturas ambientais estratégicas, sobretudo terra e água; f) conflitos socioambientais; g) pressão sobre o solo, sobretudo em função da falta de acesso à terra urbana e rural; g) dinâmica de expansão espacial horizontal e; g) falta de regulação.

\section{Os limites institucionais da divisão urbano/rural}

As diversas conceituações do rural e do periurbano apresentadas anteriormente fundamentam leituras do espaço que permitem discutir, sob diferentes enfoques, os critérios utilizados na delimitação do que se considera como rural e urbano na atualidade. Enquanto, no Brasil, as formas jurídicas de ocupação do solo se limitam à dicotomia urbano/rural, como veremos adiante, em outros países como os Estados Unidos, França e membros da OCDE houve um esforço em redefinir estes critérios de modo que levassem em conta tanto as especificidades do rural, quanto as dinâmicas estabelecidas com as cidades.

Deste modo, cabe aqui destacar algumas delimitações do rural cujos critérios permitem gradações deste espaço em relação ao urbano e que podem oferecer um embasamento mais preciso para a discussão das dinâmicas que envolvem o rural em regiões metropolitanas brasileiras. 
Neste âmbito, Abramovay (2003) discorre a respeito da proposta do novo recorte territorial na França, elaborada pelo Intitut National de la Satistique et des Études Économiques (INSEE), que estabelece as seguintes categorias:

Os espaços de predominância urbana, no qual vivem 76\% da população francesa em 13.300 comunas, que são compostos pelos polos urbanos juntos das comunas periurbanas:

1. Pólos urbanos: que oferecem ao menos 5 mil empregos com população mínima de 8 e 10 mil habitantes; e pela

2. Coroa periurbana: formada por um conjunto de comunas das quais uma elevada proporção da população ativa (ao menos $40 \%$ do total) trabalha nos polos urbanos ou nas comunas periurbanas sob influência destes polos (p.43).

3. Os espaços predominantemente rurais, que são compostos por:

4. Rural com fraca influência urbana: situa-se, como numa auréola, em torno dos espaços predominantemente urbanos e constitui-se de comunas das quais ao menos $20 \%$ dos ativos vão trabalhar num centro urbano;

5. Pólos rurais: pequenas unidades urbanas que oferecem entre 2 mil e 5 mil empregos e possuem mais postos de trabalho que a população residente, sendo, portanto, locais de atração e desempenham um papel estruturador no espaço circundante;

6. Periferia dos pólos rurais: comunas onde ao menos $20 \%$ da população ativa trabalha diariamente nos pólos rurais; e

7. Rural isolado, representando $10 \%$ da população francesa e um terço do território (p.44).

Ao analisar este recorte, o autor destaca o reconhecimento da existência de áreas rurais inteiramente sob a influência de grandes cidades, o que os franceses chamam de rural periurbano. Nestes territórios, observa-se um aumento na quantidade de segundas residências rurais, mostrando claramente a preferência crescente da população urbana por atrativos naturais (Abramovay, 2003).

De maneira similar ao recorte francês, a delimitação americana, também analisada por Abramovay (2003), busca categorizar os espaços rurais em sua heterogeneidade a partir das relações que se estabelecem com as cidades. Neste caso, o recorte proposto pelo Serviço de Pesquisa Econômica do Departamento de Agricultura dos Estados Unidos (ERS/USDA) se fundamenta no princípio de continuum rural-urbano visando não necessariamente uma 
separação entre áreas urbanas e rurais, mas entre áreas metropolitanas e áreas nãometropolitanas. Segundo o autor, o mais importante nesta definição:

"é a existência de códigos do continuum rural-urbano (rural-urban continuum codes) e de códigos de influência urbana (urban influence codes): trata-se de uma classificação para todos os condados norte-americanos que os descreve pelo grau de urbanização e de proximidade de uma área metropolitana" (Abramovay, 2003, p.38).

Desta delimitação inicial, os pesquisadores do ERS/USDA aprofundam esta classificação procurando compreender as dinâmicas espaciais com base em dois critérios: o tamanho da aglomeração populacional de cada condado e a maneira como se liga a centros mais dinâmicos, resultando na configuração que pode ser vista na tabela 1.

\begin{tabular}{|c|c|c|c|c|c|c|c|c|c|}
\hline \multirow{3}{*}{ Condados } & \multirow{2}{*}{\multicolumn{2}{|c|}{ Metropolitanos }} & \multicolumn{7}{|c|}{ Não-metropolitanos } \\
\hline & & & \multicolumn{2}{|c|}{$\begin{array}{l}\text { Adjacentes a } \\
\text { metropolitanas } \\
\text { grandes }\end{array}$} & \multicolumn{2}{|c|}{$\begin{array}{c}\text { Adjacentes a } \\
\text { metropolitanas } \\
\text { pequenas }\end{array}$} & \multicolumn{3}{|c|}{ Não-adjacentes } \\
\hline & Grandes & Pequenos & $\begin{array}{l}\text { Com } \\
\text { cidade }\end{array}$ & $\begin{array}{l}\text { Sem } \\
\text { cidade }\end{array}$ & $\begin{array}{l}\text { Com } \\
\text { cidade }\end{array}$ & $\begin{array}{l}\text { Sem } \\
\text { cidade }\end{array}$ & $\begin{array}{l}\text { Com } \\
\text { cidade }\end{array}$ & $\begin{array}{l}\text { Com } \\
\text { town }\end{array}$ & $\begin{array}{l}\text { Totalmente } \\
\text { rural }\end{array}$ \\
\hline 3.141 & 311 & 525 & 63 & 123 & 188 & 627 & 234 & 555 & 515 \\
\hline
\end{tabular}

Tabela 1: Condados norte-americanos segundo tamanho da população e variações em sua influência urbana (Abramovay, 2003, p. 40)

Ambos exemplos demonstram a necessidade de discutir não somente a tipologia do rural brasileiro, para orientar políticas públicas mais amplas, como também sua regulamentação, para orientar políticas e parâmetros de ordenamento territorial. Essa questão é especialmente importante no caso das regiões metropolitanas, em que a proximidade com grandes centros urbanos é determinante na caracterização da ruralidade nestas áreas, o que aumenta a vulnerabilidade de transformação do rural para o urbano.

\section{O urbano e o periurbano na Região Metropolitana de São}

\section{Paulo}

As regiões metropolitanas brasileiras caracterizam-se, em um primeiro olhar, por uma dualidade expressiva da ocupação do solo. Possuem áreas urbanas com altas densidades construtivas (que nem sempre são acompanhados de densidades populacionais) e, fora da mancha, espaços com baixa densidade de ocupação e com grandes parcelas de 
remanescentes de vegetação, atividade agrícola e chácaras de recreio, em alguns casos, protegidos por legislação ambiental.

Na Região Metropolitana de São Paulo, a mancha urbana se expandiu a taxas elevadas até os anos 1990. Após essa década, esse crescimento se arrefeceu, porém, a periferia permanece em processo de crescimento domiciliar e populacional elevado (IBGE, 1991; 2000; 2010), em comparação com o crescimento das áreas com infraestrutura. Isso indica que, apesar das menores taxas, ainda há uma pressão pela urbanização das franjas.

Também se observa na região um aumento do processo de urbanização dispersa, conforme analisado por Silva (2013) entre os anos de 1989 e 2010. Esse processo leva a constituição cada vez maior de uma área periurbana, em um mosaico extremamente complexo de usos do solo (Capel, 1994), conformando-se como um lugar de disputa entre as políticas urbanas, as atividades de cunho rural e a proteção ambiental.

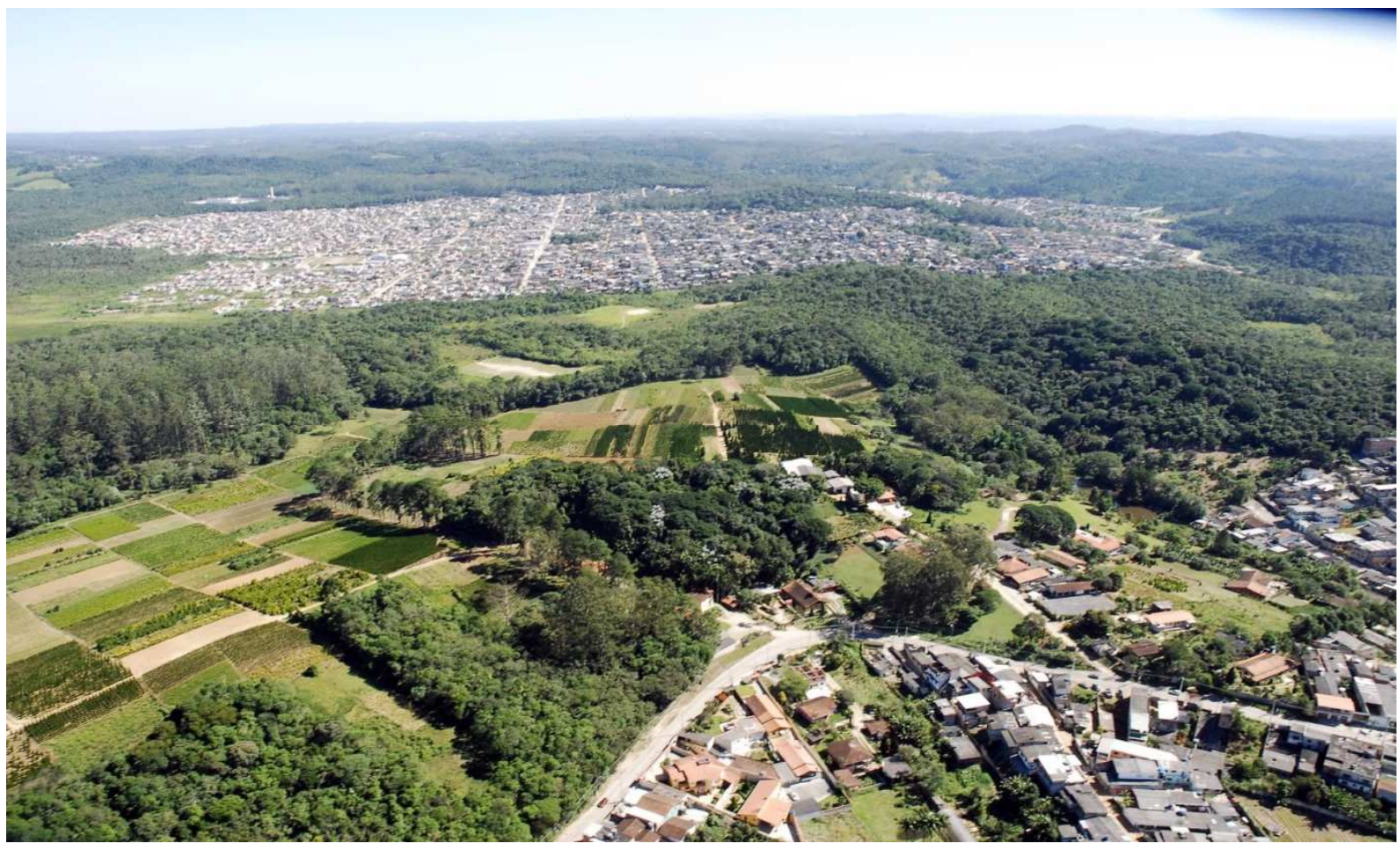

Figura 1: Ao fundo, ocupação da Cratera de Colônia, em Parelheiros, Município de São Paulo

(Travassos, 2014)

A mancha urbana da RMSP é circundada por um cinturão verde, que foi certificado como Reserva da Biosfera do Cinturão Verde da Cidade de São Paulo pela Unesco, em 1993. Mesmo antes disso, a região sul e parte da região norte da metrópole foram consideradas Áreas de Proteção e Recuperação de Mananciais, regulamentadas pela lei estadual n. 9866 
de 1997, que complementou e modificou as leis estaduais n. 898, de 1975, e 1.172, de 1976. Essa nova legislação ensejou, recentemente, a criação de uma lei específica para cada bacia. Há ainda na região uma série de Unidades de Conservação de Uso Sustentável e de Proteção Integral, nas esferas municipal e estadual. Assim, parcela considerável do território está sob proteção ambiental de uso sustentável, conforme instituída pelo Sistema Nacional de Áreas de Conservação (Lei Federal n. 9.985, de 2000) - ou seja, permite atividades econômicas e residenciais, um tipo de regulação do uso e ocupação do solo que dificilmente é capaz de consolidar um tipo uma forma específica de ocupação da terra, mas que pode dar suporte para a conformação de áreas rurais ou periurbanas. Por outro lado, dadas as intensas e multiescalares dinâmicas metropolitanas, possuif um caráter de grande transitoriedade.

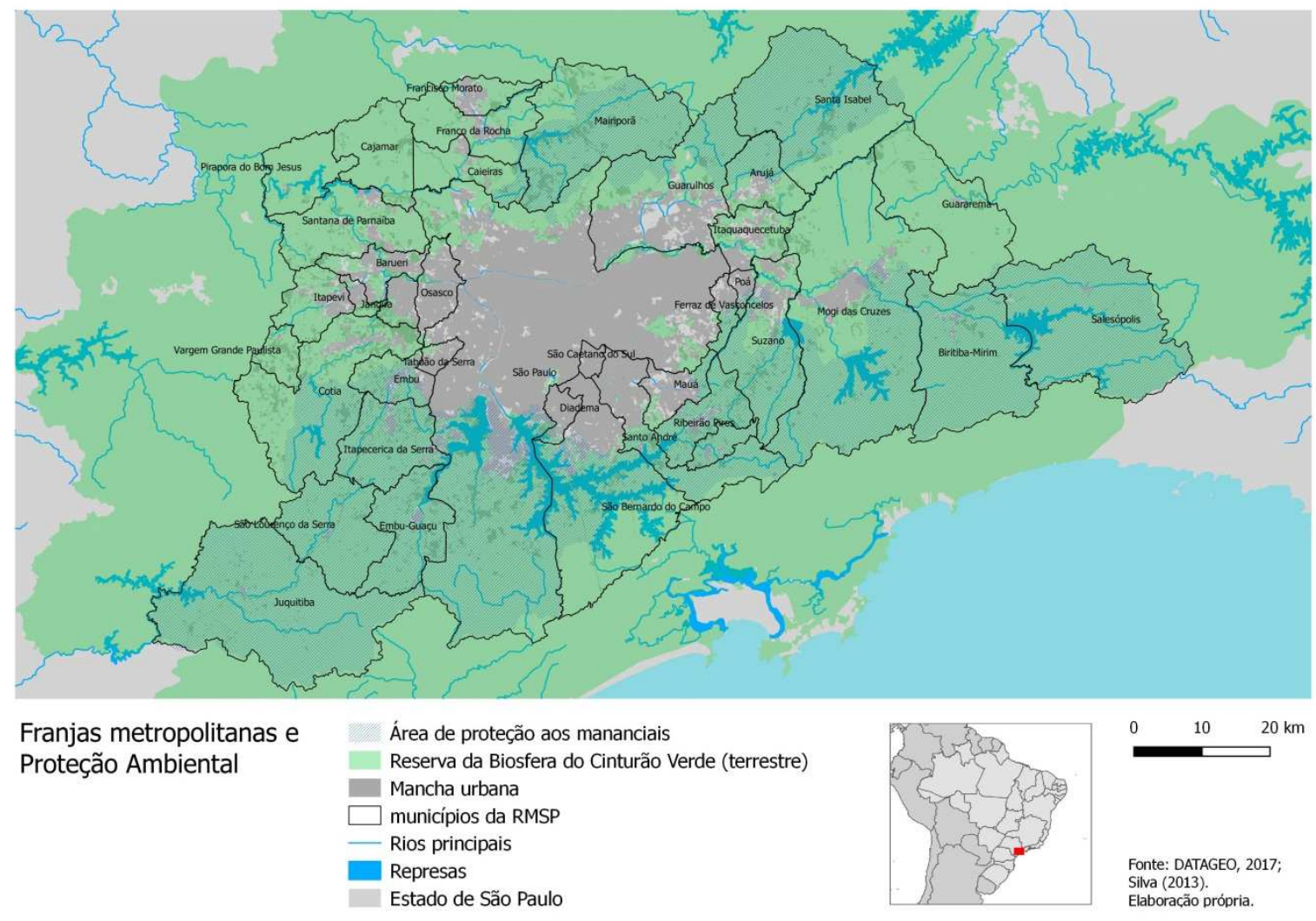

Figura 2: Franjas metropolitanas e proteção ambiental

Tais áreas prestam uma série de serviços ecossistêmicos (MEA, 2005) essenciais à metrópole, em especial os de regulação, como o controle climático, de inundação e estiagem e os de suporte, como formação do solo e ciclagem de nutrientes, e os culturais, como recreação e cultura. Os serviços de provisão como, o fornecimento de alimentos - que na região tem como principais atividades a produção de hortaliças e frutas -, mesmo com a 
expansão crescente da mancha urbana e principalmente com os atuais padrões de urbanização dispersa, mantém-se na média, por volta de 117 mil hectares em 1995/1996 e 114 mil hectares em 2007/2008, descontados os municípios que não possuíam dados para um dos períodos. As médias, no entanto, escamoteiam situações muito diversas, uma forte diminuição em alguns municípios, tanto do ponto de vista relativo quanto absoluto, como é o caso de Juquitiba na região sudoeste, e aumento em outros, como Salesópolis, no extremo leste. Esses dois municípios representam a relativa polaridade que se observa entre o leste e o oeste da metrópole, como pode ser visto nos mapas abaixo, produzidos a partir dos dados do Levantamento Censitário de Unidades de Produção Agropecuária, LUPA 1995/1996; 2007/2008 (São Paulo, SSA, 2016).

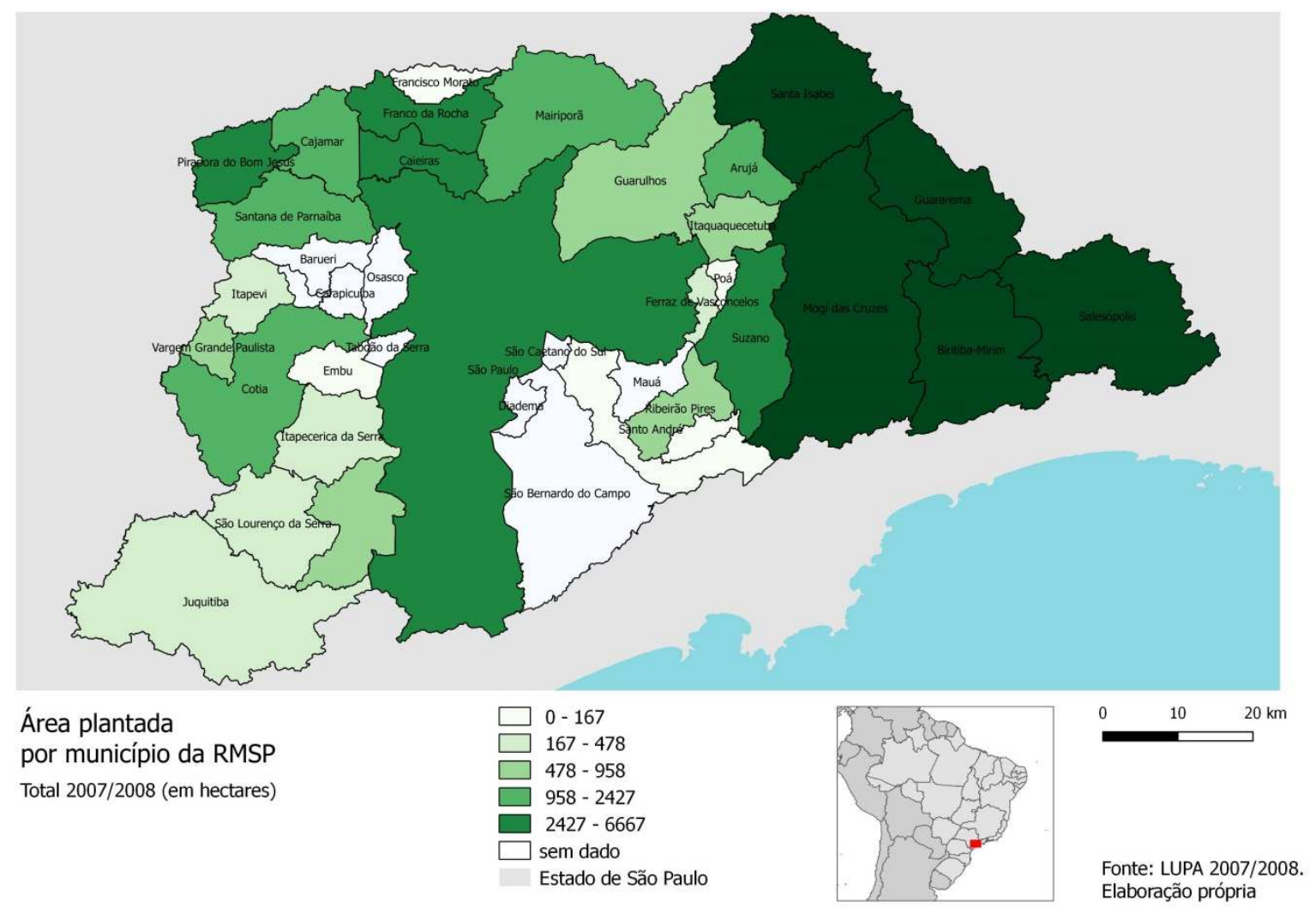

Figura 3: Área plantada por município da RMSP 2007/2008. 


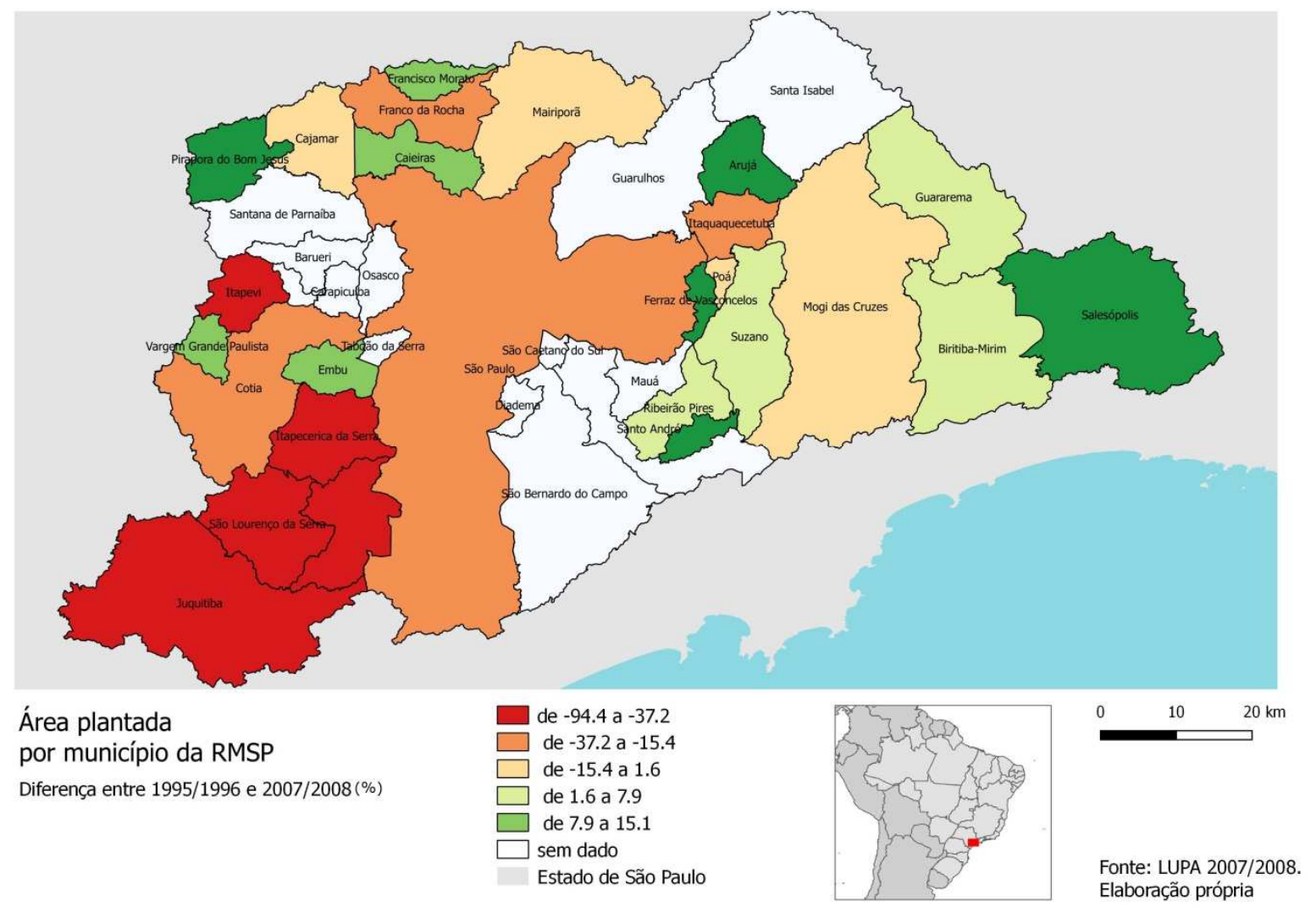

Figura 4: Área plantada por município da RMSP. Diferença entre 1995/1996 e 2007/2008

Os dados existentes não permitem uma análise das dinâmicas mais recentes, o LUPA 2007/2008 é o último levantamento de agropecuária produzidos no Estado de São Paulo, o que se constitui como uma dificuldade para a análise desta atividade. A base nacional, Censo Agropecuário, cuja última versão é de 2006 (IBGE, 2006), está em processo de levantamento de dados e deve ser disponibilizada em 2018.

Para além da produção agrícola, como pode ser visto nas figuras 5 a 8, esse cinturão verde possui muitas outras atividades econômicas, culturais e de lazer, como pesqueiros, sítios de lazer, casas de campo, produção de frutas e flores, clubes, estruturas de turismo ecológico e rural e seus serviços, como restaurantes, hotéis, pousadas, entre outros usos. Ao sul da metrópole, na Capital e em São Bernardo do Campo, há ainda uma terra indígena, ampliada recentemente. 

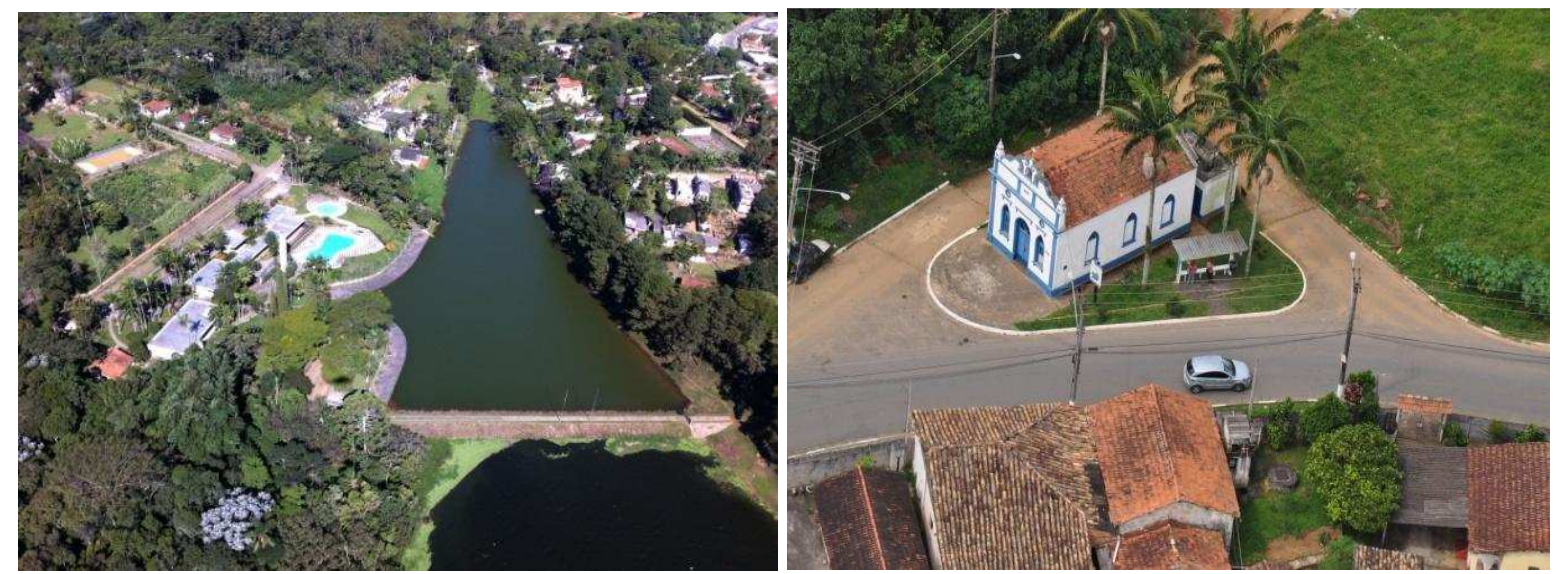

Figuras 5 e 6: fotos aéreas da Casa Modernista e Igreja de São Sebastião, na llha de Bororé, zona sul do município de São Paulo (Travassos, 2013).

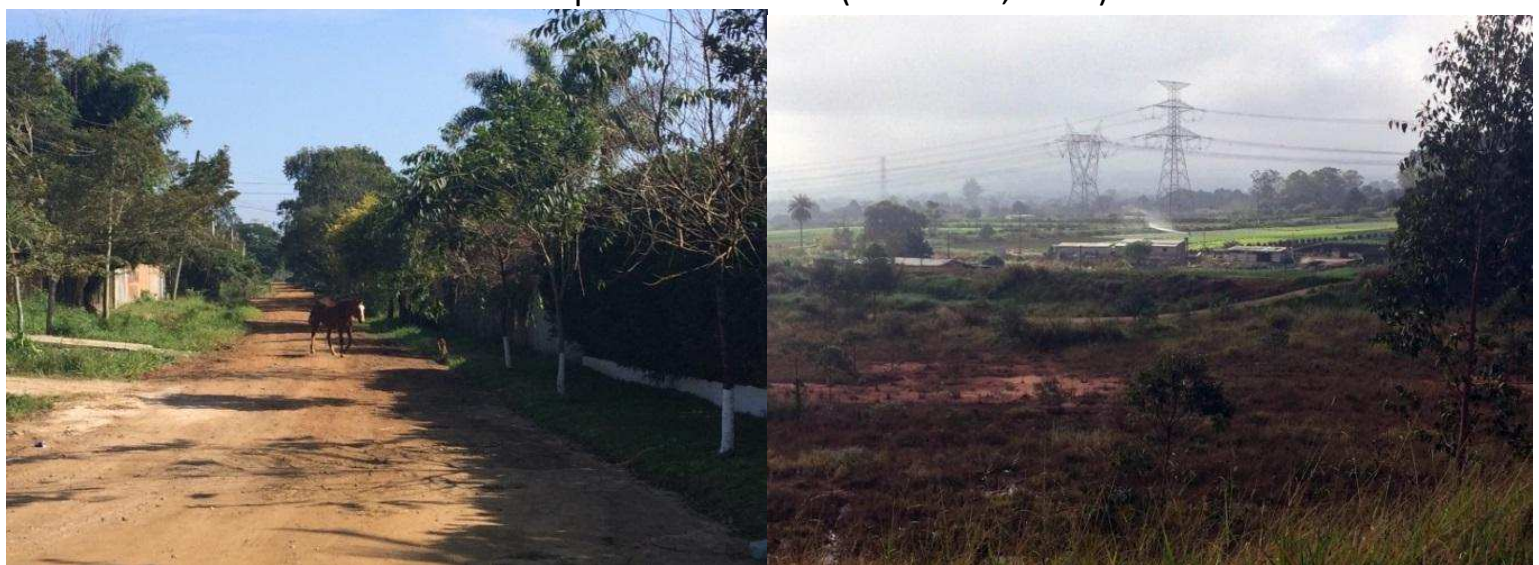

Figuras 7 e 8: Região da represa de Taiaçupeba, Mogi das Cruzes, região leste da RMSP (Travassos, 2017).

Considerando as questões discutidas anteriormente acerca das visões contemporâneas sobre o rural e o crescente processo de integração entre o rural e o urbano, é possível dizer que as franjas metropolitanas na RMSP se configuram como espaço de pluriatividade e multifuncionalidade e guardam uma grande proximidade com as dinâmicas da natureza, com funções agrícolas, ambientais e culturais, podendo ser consideradas como uma zona rural e periurbana.

Dois estudos atuais procuram ampliar o entendimento do rural brasileiro. 0 projeto Tipologia Regionalizada dos Espaços Rurais Brasileiros (Bitoun et al., 2017) propôs construir uma representação capaz de abarcar a heterogeneidade dos territórios rurais brasileiros, identificando 26 tipos de espaços rurais, relacionados aos seis macrobiomas do país. Embora este trabalho tenha o mérito de proporcionar um olhar inédito sobre esses territórios, realizando um extenso levantamento que cruza dados históricos, naturais, geográficos, critérios espaciais, e indicadores sociais, demográficos e culturais para definição 
das tipologias regionalizadas, toda a metodologia utilizada no projeto não considera, desde o princípio, os municípios localizados em metrópoles e capitais federais. Tal decisão se pauta no argumento de que, para os 376 municípios que integram metrópoles no Brasil, seria necessária uma metodologia específica, que também considerasse a agricultura urbana e periurbana (Bitoun et al, 2017).

Mais recentemente, o Instituto Brasileiro de Geografia e Estatística lançou um estudo em que procura complexificar a divisão tradicionalmente utilizada pelo instituto entre rural e urbano, reconhecendo sua limitação. Inseriu em seus parâmetros o conceito de localização e isolamento (com relação aos Estados e ao país) e tamanho e densidade populacional (IBGE, 2017). O resultado confere ao Brasil uma análise muito diferente de seu rural, ampliando-o e tornando menos estanque que as duas categorias originais, mas segue insuficiente para revelar o rural metropolitano. Na RMSP, somente os municípios de Guararema e Juquitiba passam a ser considerados como "rural adjacente", os demais seguem como "predominantemente urbano".

Com relação à regulação, boa parte da RMSP é considerada urbana. Isso se deve ao fato que, institucionalmente, no Brasil, há somente duas categorias de uso da terra legalmente estabelecidas, o urbano e o rural, dadas por uma série de instrumentos legais e instituídas a partir, muitas vezes, de interesses locais.

A primeira definição que as separa é o tipo de propriedade. A rural é definida pela sua utilização econômica, assim o Estatuto da Terra (Lei Federal n. 4504 de 1964) define Imóvel Rural, como uma área rústica, contínua, em qualquer localização que se destine à exploração extrativa agrícola, pecuária ou agroindustrial, o que é reconfirmado pela Lei Federal n. 8629 de 1993, que regulamenta a Constituição Federal de 1988. O imóvel urbano, por sua vez, é aquele resultante de parcelamento do solo urbano (Lei Federal n. 6.766 de 1979), cuja infraestrutura básica deve ser constituída por escoamento das águas pluviais, iluminação pública, esgotamento sanitário, abastecimento de água potável, energia elétrica pública e domiciliar e vias de circulação (Lei Federal n. 11.445 de 2007). Outra definição surge no Código Tributário Nacional e na Lei do Imposto Territorial Rural (Lei Federal n. 9393 de 1996), cujo texto estabelece que é rural o imóvel localizado na zona rural, definida em lei municipal, o mesmo se estabelece sobre a expansão do perímetro urbano, que deve constar 
do Plano Diretor Municipal ou de outra lei também nesse âmbito federativo (Lei Federal $\mathrm{n}$. 9.785 de 1999).

Assim, embora as definições não sejam completamente convergentes nas diversas leis, cabe aos municípios estabelecer, em seus territórios, as zonas urbanas e, portanto, as zonas rurais. Nas regiões metropolitanas, parte significativa dos municípios eliminaram completamente as zonas rurais, independentemente das condições de ocupação da terra ou das possibilidades de ampliação da urbanização - mais controladas a partir da aprovação da Política Nacional de Proteção e Defesa Civil (Lei Federal n. 12.608 de 2012).

Por outro lado, parte dessas áreas também não se enquadra nos parâmetros estabelecidos para as zonas rurais no país, em especial no que se refere às restrições ao parcelamento, como o tamanho mínimo da propriedade. Na RMSP, o módulo fiscal rural varia entre 5 a 7 hectares, enquanto mesmo as propriedades destinadas à produção agrícola possuem tamanho menor; em Mogi das Cruzes, por exemplo, o município com maior produção agrícola da região, de 1616 propriedades, que perfazem cerca de 26 mil hectares, 745 possuem menos que 5 hectares (São Paulo, SSA, 2016), gerando grandes problemas para a regularização fundiária rural.

Assim, é possível dizer que o rural e o periurbano metropolitanos têm dificuldade em serem identificados como o são, não contando com um lugar nas políticas públicas dos municípios muito urbanizados - que raramente possuem políticas de viés rural -, além de não serem alcançado pelas políticas estaduais ou federais de fomento e assistência ao rural. A existência desse vácuo institucional implica em uma perda de importância das atividades rurais e na fragilização da proteção ambiental. O crescimento urbano não encontra barreiras, então, para além de sua regulação, muitas vezes, inadequada ou insuficiente. Ele se estabelece nas áreas rurais ou periurbanas, protegidas ou não pelas leis ambientais, diminuindo a capacidade de produção agrícola e outras atividades, como as de turismo e lazer. Esse crescimento aumenta a fragmentação da vegetação e dos usos do solo, dificultando tanto a manutenção dos serviços ecossistêmicos quanto a própria gestão da terra, uma vez que tais territórios não se incorporam perfeitamente com as normas de uso da terra existentes. 


\section{Considerações finais}

Com base nas definições conceituais de rural e periurbano apresentadas anteriormente, cabe ressaltar que não se buscou aqui escolher a melhor definição para estes territórios, mas levantar as contribuições dos autores destas temáticas no intuito de se obter ferramentas para compreender e debater o rural nas metrópoles e sua regulamentação, na RMSP.

Nesse sentido, a bibliografia aqui apresentada converge em alguns pontos: o primeiro é o de que o rural não é estático e sua compreensão deve considerar não apenas as características inerentes a estes espaços, mas, sobretudo, as dinâmicas que configuram estes territórios, as relações destes com as cidades e as centralidades rurais (Abramovay, 2003; Kageyama, 2008; Favareto e Wanderley, 2013). Um segundo ponto, também igualmente relevante é o de que a compreensão da diversidade rural deve considerar não apenas as dinâmicas demográficas e sócio-produtivas, mas também as estruturas sociais, os arranjos institucionais formais e informais e as formas de ação coletiva que se dão nestes territórios, que também não são estáticas, mas se transformam no tempo e no espaço (Berdegué et al., 2012).

Outro ponto relevante é que, para se compreender o rural metropolitano, é preciso considerar os conceitos referentes às áreas de interface periurbanas. Embora nos estudos do rural a partir das dinâmicas estabelecidas com cidades pequenas e médias não considere a relevância destas áreas, no contexto dos municípios localizados em regiões metropolitanas, a escala da interface periurbana é fundamental, podendo haver municípios em que o rural por si só nem possa ser considerado. Deste modo, se mostra relevante discutir o que há de rural e de periurbano nestes municípios.

Contudo, a literatura aqui apresentada aponta que há de se ter certa cautela ao trabalhar com estes dois conceitos. Se por um lado as discussões a respeito dos conceitos do espaço rural e das características da nova ruralidade demonstram certa homogeneidade quanto ao objeto de estudo, o mesmo não pode ser dito dos conceitos de periurbano, o que torna difícil sua utilização enquanto ferramenta analítica das dinâmicas que configuram o rural na metrópole, sendo frequentemente necessário buscar o que os autores entendem, a priori, como urbano e rural. Além disso, como aponta Furtado (2007), os estudos das áreas 
periurbanas não superaram uma conceituação dicotômica entre os fenômenos rural e o urbano, no qual prevalece uma visão do urbano sobre o rural, em uma abordagem que desconsidera o dinamismo do rural. Esta perspectiva está na contramão da literatura sobre a nova ruralidade, uma vez que esta parte do princípio da diversidade e dinamismo do rural e das relações que se estabelecem com o urbano.

Por fim, diante da ruralidade contemporânea, há que se ponderar que as fronteiras entre o rural e o urbano tornam-se mais fluidas em relação aos traçados legais das sedes urbanas e das áreas rurais, na qual se entende que a escala para se pensar o desenvolvimento não se restringe ao local, ao espaço rural, ao espaço urbano, mas evidencia o território como o lugar da ação intersetorial de políticas públicas, de reconhecimento e valorização de aspectos culturais, garantia da sustentabilidade ambiental, espaço da reprodução social e da integração de mercados (Bitoun, et al., 2017, p.458).

Assim, cabe ressaltar que o reconhecimento institucional dos espaços rurais e periurbanos na metrópole é especialmente importante para que a regulação de usos da terra possa se adequar à complexidade desses territórios como base para a elaboração de projetos de desenvolvimento e de políticas públicas. Em se tratando da RMSP, este reconhecimento ganha relevância, na medida em que se observa, por um lado, o crescimento populacional acentuado nas áreas rurais e periurbanas, protegidas ou não por leis ambientais; e por outro, uma centralidade do viés urbano nas políticas para estes espaços e um vácuo institucional a respeito das áreas de interface periurbana, implicando na perda de importância do rural e na fragilização da proteção ambiental, restando poucas barreiras ao crescimento urbano (Travassos \& Ferreira, 2016).

\section{Referências bibliográficas}

ABRAMOVAY, Ricardo. Funções e medidas da ruralidade no desenvolvimento contemporâneo. In ABRAMOVAY, R. O Futuro das Regiões Rurais. Porto Alegre: Editorada UFRGS, 2003, p. 17-56.

AGRICULTURAL ECONOMICS RESEARCH INSTITUTE (LEI). Rural areas under urban pressure; Case studies of rural-urban relationships across Europe. Overbeek, M.M.M. and I.J. Terluin (eds.). Report 7.06.01. The Hague, 2006.

BARSKY, Andrés. El Periurbano Productivo, um espacio em constante transformación. Introducción al estado del debate, com referencias al caso de Buenos Aires. Revista Electrónica de Geografía y Ciencias Sociales. Universidad de Barcelona. ISSN: 1138-9788. Depósito Legal: B. 21.741-98 Vol. IX, núm. 194 (36), 1 de agosto de 
2005.

BERDEGUÉ, et al. Territorios en Movimiento. Dinámicas territoriales rurales en America Latina. Documento de trabalho N 110. Programa Dinámicas Territoriales Rurales. Rimisp, Santiago, Chile. 2012.

BITOUN, et al. Tipologia Regionalizada dos Espaços Rurais Brasileiros, in Tipologia Regionalizada dos Espaços Rurais Brasileiros: implicações no marco jurídico e nas políticas públicas/Carlos Miranda (Organizador da Série). Brasilia. : IICA, 2017 (Série Desenvolvimento Rural Sustentável; v. 22)

Brasil, Instituto Brasileiro de Geografia e Estatística (IBGE). Censo agropecuário. Rio de Janeiro: IBGE, 2006

Brasil, Instituto Brasileiro de Geografia e Estatística (IBGE). Censos demográficos 1991, 2000 e 2010. Rio de Janeiro: IBGE, 2016

CARDOSO, Maria Mercedes \& FRITSCHY, Bianca Argentina. Revisión de la Definición del Espacio Rururbano y sus Criterios de Delimitación. Contribuiciones Cientificas GEAEA. V. 24, p. 27-39. 2012.

FAVARETO, Arilson \& WANDERLEY, Maria de Nazareth Baudel. A Singularidade do Rural Brasileiro: implicações para tipologias territoriais e a elaboração de políticas públicas. Relatório final do projeto "Repensando o Conceito de Ruralidade no Brasil". Instituto Interamericano de Cooperação Agrícola - IICA. Brasília, Fevereiro/2013.

FURTADO, F.G.. A Gestão Urbana e Regional e as Áreas de Interface Periurbana. In: XII Encontro Nacional da ANPUR, 2007, Belém. Anais do XII Encontro Nacional da ANPUR, 2007.

KAGEYAMA, Angela A. Desenvolvimento Rural: conceitos e aplicação ao caso brasileiro. Porto Alegre: UFRGS Editora, 2008.

MARQUES, Hélder. Porquê (e razões para) a mitificação do campo, VII Colóquio Ibérico de Estudos Rurais - Cultura, Inovação e Território, Coimbra. 2008.

MARQUES, Hélder. O verde produtivo na AMP no horizonte 2020. (GOT), n. 7 (junho). Centro de Estudos de Geografia e Ordenamento do Território, p. 213-229. 2015. dx.doi.org/10.17127/got/2015.7.009

MARQUES, M. I. M. O conceito de espaço rural em questão. Revista Terra Livre. 2002, n.19, p.95-112. portal.mda.gov.br/o/3467997

Millennium Ecosystem Assessment (MEA). Ecosystems and Human Well-being: Synthesis. MEA: 2005. Disponivel em: http://www.unep.org/maweb/ documents/document.356.aspx.pdf Acesso em: 03 out. 2016.

REGIDOR, Jesús G. Territorial Agriculture and Rural Development: From Agricultural Support to Territorial Policies. In OECD. The Future of Rural Policy: from sectoral to place-based policies in rural areas. OECD Publications, Paris, França, 2003.

SÃO PAULO (Estado). Secretaria de Agricultura e Abastecimento. Coordenadoria de Assistência Técnica Integral. Instituto de Economia Agrícola. Levantamento censitário de unidades de produção agrícola do Estado de São Paulo - LUPA, 1995/1996; 2007/2008. São Paulo: SAA/CATI/IEA, 2008. Disponível em: http://www.cati.sp.gov.br/projetolupa em out. de 2016.

SÁNCHEZ, Hector Ávila. Periurbanización y espacios rurales em la periferia de las ciudades. 2009.

SILVA, Graziano da. O Novo Rural Brasileiro. Revista Nova economia, Belo Horizonte. 7(1):43-81. Maio/1997.

SILVA, Lucia Sousa e. "A cidade e a floresta: o impacto da expansão urbana sobre áreas vegetadas na Região metropolitana de São Paulo (RMSP)". Tese de doutorado apresentada ao Procam-USP. São Paulo: 2013.

SILVA, Luís. A procura do turismo em espaço rural. Etnográfica [Online], vol. 11 (1) | 2007, Online since 25 September 2012, connection on 29 October 2017. URL : http://etnografica.revues.org/1896 ; DOI : 10.4000/etnografica.1896

TRAVASSOS, L. \& FERREIRA, R. C. O Periurbano e o Rural Metropolitanos: desafios para a elaboração do Plano Diretor Regional do Grande ABC. III Congresso Internacional de Gestão Territorial para o Desenvolvimento Rural - Mudanças Globais e Locais: implicações para as dinâmicas de desenvolvimento territorial. Brasília, 2016. 